\title{
Effects of dietary zinc deficiency on the reproductive system of young male sheep: testicular growth and the secretion of inhibin and testosterone
}

\author{
G. B. Martin ${ }^{1,2}$, C. L. White ${ }^{2}$, C. M. Markey ${ }^{3}$ and \\ M. A. Blackberry ${ }^{1}$ \\ ${ }^{1}$ School of Agriculture (Animal Science), The University of Western Australia, Nedlands, WA 6009, \\ Australia; ${ }^{2}$ CSIRO Division of Animal Production, Private Bag, Wembley, WA 6014, Australia; and \\ ${ }^{3}$ Department of Anatomy and Human Biology, The University of Western Australia, Nedlands, \\ WA 6009, Australia
}

The effects of dietary zinc deficiency on testicular development in young Merino rams (initial live mass, $22 \mathrm{~kg}$ ) were tested. Four groups of five rams were fed ad libitum with diets containing 4, 10, 17 or $27 \mu \mathrm{g} \mathrm{Zn} \mathrm{g}{ }^{-1}$. To control the effects of loss of appetite caused by zinc deficiency, a fifth group (pair-fed control) was fed the diet containing $27 \mu \mathrm{g} \mathrm{Zn} \mathrm{g}^{-1}$, but the amount of feed offered was restricted to that eaten voluntarily by the zinc deficient $\left(4 \mu \mathrm{Zn} \mathrm{g}^{-1}\right)$ rams they were paired with. After 96 days on the diets, epididymal and testicular masses did not differ significantly between the animals fed 10,17 or $27 \mu \mathrm{g} \mathrm{Zn} \mathrm{g}^{-1}$ ad libitum, but were significantly lower in pair-fed controls, and lowest in the zinc-deficient animals. Testicular responsiveness to $\mathrm{LH}$, as measured by testosterone production, increased substantially in most rams as the experiment progressed, the only exception being the zinc-deficient group, in which the response to LH was lower than in any of the other groups. Testicular concentrations of zinc and testosterone were lower in the zinc-deficient animals than in all the other groups. Plasma inhibin concentrations fell as the experiment progressed in rams fed 17 and $27 \mu \mathrm{g} \mathrm{Zn} \mathrm{g}^{-1}$ ad libitum, but not in the other groups. The pair-fed control rams had smaller seminiferous tubules and less lumen development than did the controls fed ad libitum (27 $\mu \mathrm{g} \mathrm{Zn} \mathrm{g}{ }^{-1}$ ), which were similar to the animals fed 10 or $17 \mu \mathrm{g}$ $\mathrm{Zn} \mathrm{g}^{-1}$. In zinc-deficient rams, the tubule development was further retarded and the interstitial regions were more extensive than in the other groups. We conclude that the overall effect of zinc deficiency on testicular development is due to a combination of a non-specific effect (low gonadotrophin concentrations caused by the low feed intake) and a specific effect due to the lack of zinc. The zinc-specific effect is localized within the testis where it reduces the development of the capacity to produce testosterone, leading to low intratesticular concentrations of testosterone, a critical factor for the growth, development and function of the seminiferous tubules.

\section{Introduction}

Zinc is an essential trace element and many physiological processes are impaired if it is not supplied in sufficient quantities in the diet. Underwood and Somers (1969) suggested that there may be two degrees of zinc deficiency in growing rams: 'severe' deficiency (less than $5 \mu \mathrm{g} \mathrm{g}^{-1}$ in the diet), which induces skin lesions (parakeratosis), low growth rates and poor testicular development; and 'mild' deficiency (5-17 $\left.\mu \mathrm{g} \mathrm{g}^{-1}\right)$, where there are no clinical signs and body growth is normal, but testicular development and sperm production are markedly reduced. This type of 'sub-clinical' deficiency might explain the poor reproductive performance of

Received 19 July 1993 sheep grazing zinc-deficient pastures (Masters and Fels, 1980; Masters and Somers, 1980).

These observations led us to examine the hormonal systems controlling testicular growth in rams fed diets containing 4-27 $\mu \mathrm{g} \mathrm{Zn} \mathrm{g}^{-1}$ (Martin and White, 1992). We concluded that a large proportion of the reduction of testicular growth in the rams fed a zinc-deficient diet is due to the secretion of a low frequency of pulses of $\mathrm{GnRH}$ by the hypothalamus, leading to low rates of gonadotrophin secretion by the pituitary gland. This effect was not specifically related to the trace element, but was primarily due to the fall in feed intake caused by the loss of appetite, one of the clinical signs of deficiency.

However, some of the loss in testicular growth was associated specifically with low zinc intake (Martin and White, 1992), an observation supported by studies in humans, pigs and rats, Downloaded from Bioscientifica.com at 04/26/2023 01:08:54AM
and Fertility Ltd free access 
where a role for zinc in the control of testosterone synthesis or secretion has been proposed (Root et al, 1979; McClain et al., 1984; Prasad, 1985). Zinc deficiency may lead to a biochemical lesion in the pathways controlling steroid synthesis, as suggested by Lei et al. (1976), impaired development of the smooth endoplasmic reticulum in the Leydig cells, the site of testosterone synthesis (Hesketh, 1982), or a malfunction in the LH receptor mechanism controlling storage and release of testosterone, as suggested by Kellokumpu and Rajaniemi (1981). A third possibility is raised by the structural nature of steroid receptors, where zinc is an integral component of the structure that binds to DNA and regulates gene expression (the 'zinc finger' proteins; Parker, 1989). Poor steroid binding would reduce the effectiveness of intratesticular testosterone, one of the key regulators of testicular development and function (Kerr et al., 1992).

In this report, we describe the second part of our study with pubertal rams fed diets containing a range of zinc concentrations, in which we have detailed the effects of zinc deficiency on testicular growth, histology and hormone production. A preliminary report to this work was presented by Martin and White (1989).

\section{Materials and Methods}

\section{Animals and treatments}

The animals and preparation and analysis of the diets have been described in detail by Martin and White (1992) and are summarized as follows. In November (late spring), five groups of four rams (age 16 weeks; mean live mass, $22 \mathrm{~kg}$ ) were penned individually in an animal house under natural photoperiod. They were acclimatized for 2 weeks with free access to deionized water and a semi-purified chaff diet that formed the basis of the dietary treatments, except that it contained $27 \mu \mathrm{g}$ $\mathrm{Zn} \mathrm{g}^{-1}$. As well as chaff, the diet contained starch, sucrose, egg albumen and minerals, and the animals were given regular vitamin supplements by injection.

After allocation to five treatment groups, the animals in four of these groups were fed ad libitum with diets containing 27 ('ad libitum control'), 4 ('deficient'), 10 or $17 \mu \mathrm{g} \mathrm{Zn} \mathrm{g}{ }^{-1}$. The rams in the fifth group, the 'pair-fed control', were fed the diet containing $27 \mu \mathrm{g} \mathrm{Zn} \mathrm{g}^{-1}$, but each animal was paired with an animal from the deficient group and fed only the amount eaten voluntarily by its pair during the previous day. Once each week, just before feeding, the animals were weighed and the diameters of both testes were measured with calipers.

After 96 days on the dietary treatments, the animals were killed with an overdose of barbiturate and the testes and epididymides were removed, dissected and weighed. Samples (3-4 g) of testicular tissues were taken from the body of the testis for chemical and histological analysis.

\section{Zinc assay}

Zinc concentrations in samples of diet, blood plasma and testicular tissue were determined by flame atomic absorption spectroscopy (Varian model 875). Plasma was treated with an equal volume of $10 \%$ solution of analytical grade trichloro- (a)


(c)

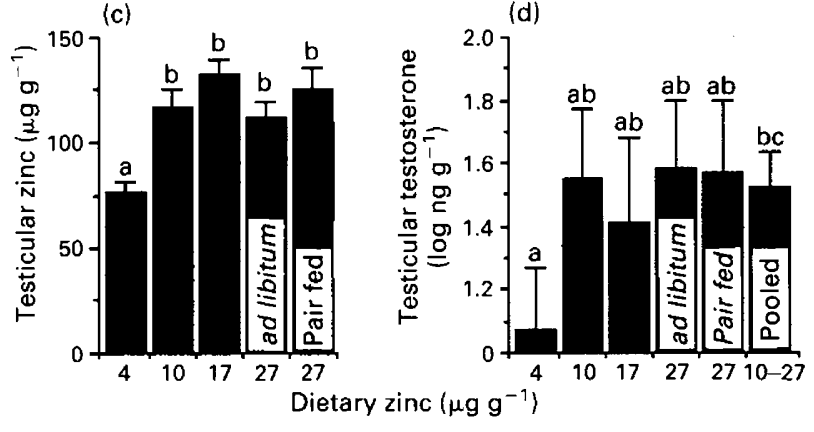

Fig. 1. Effects of dietary zinc on (a) total testicular mass, (b) total epididymal mass and the concentrations of (c) zinc and (d) testosterone in testicular tissue in young rams after 96 days of treatment. All values are means \pm SEM $(n=4)$ and the data for organ masses have been back-transformed from the logarithmic values used in the statistical analysis. ${ }^{a, b}$, c Values with different letters are significantly different (between-treatment comparison by least significant difference after analysis of variance; $P<0.05$ ).

acetic acid, the mixture was centrifuged for $15 \mathrm{~min}$ at $1500 \mathrm{~g}$, and the supernatant was analysed for zinc. Samples of the diets and testes were digested in a mixture of perchloric, nitric and sulfuric acids before analysis. All zinc concentrations were expressed on a dry weight basis.

\section{Endocrine analyses}

Serial samples of blood plasma (every $20 \mathrm{~min}$ for $32 \mathrm{~h}$ ) were taken from jugular catheters inserted on the day before sampling and used to study the secretory patterns of LH, FSH and testosterone. This was done on two occasions, just before the imposition of the diets and 92 days later near the end of the experiment. At the end of each intensive sampling period, the animals were injected with GnRH (HRF: Ayerst Laboratories Pty Ltd, Parramatta NSW; $10 \mathrm{ng} \mathrm{kg}{ }^{-1}$ in saline) and further samples were taken at 0,10 and $20 \mathrm{~min}$, and then every $20 \mathrm{~min}$ for $4 \mathrm{~h}$ after the injection. The samples following $\mathrm{GnRH}$ injection were assayed for $\mathrm{LH}$ to describe the pituitary response, and for testosterone to test the testicular responsiveness to this exogenously induced LH pulse. The LH responses were similar at all times and over all treatments (Martin and White, 1992); testosterone concentrations in the samples 40-240 min after $\mathrm{GnRH}$ injection were therefore used to calculate the areas under the testosterone curves as an estimate of testicular responsiveness to an $\mathrm{LH}$ pulse.

Downloaded from Bioscientifica.com at 04/26/2023 01:08:54AM 

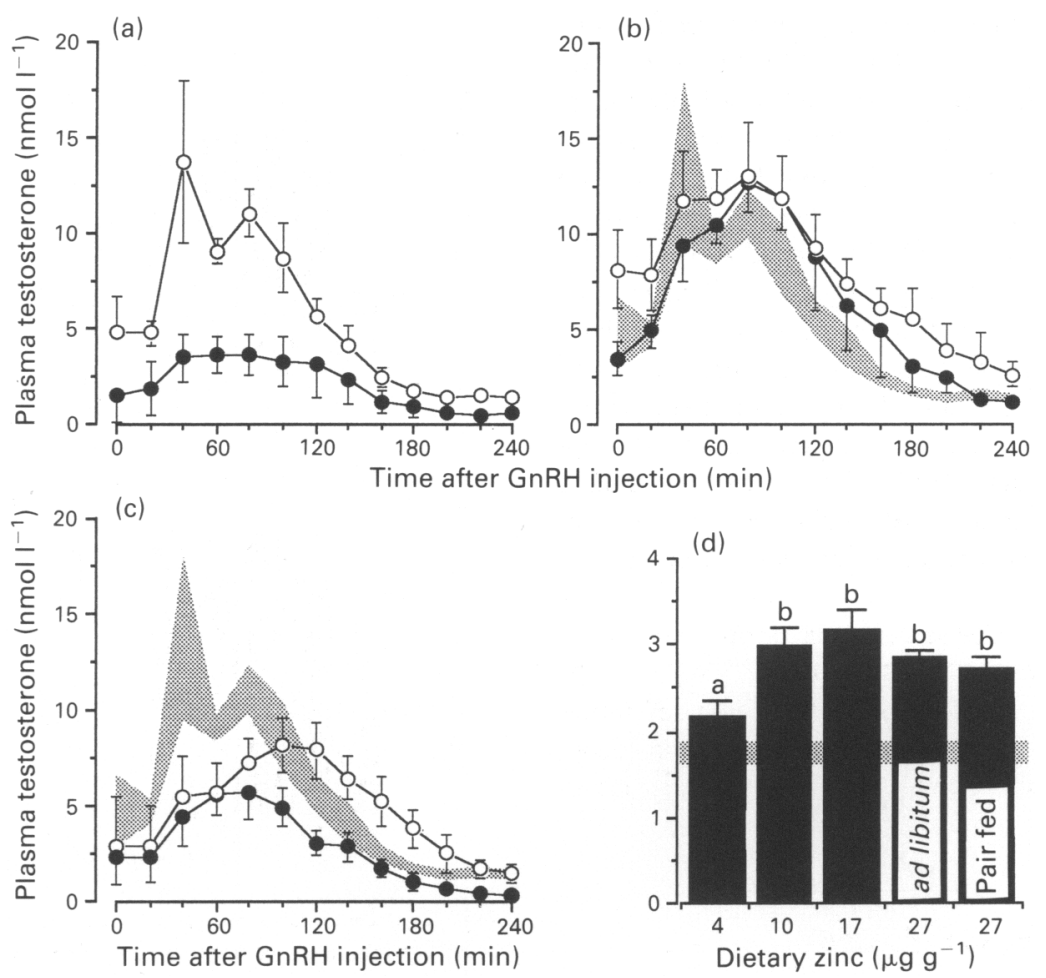

Fig. 2. Effects of dietary zinc on the testicular response of young male sheep after 92 days of treatment to an LH pulse induced by an injection of GnRH. (a) The pretreatment response ( $\bullet$ ) for the whole group $(n=20)$ is compared with the response of the group fed $27 \mu \mathrm{g} \mathrm{Zn} \mathrm{g}^{-1}$ ad libitum for 96 days (0). For comparison, the data from this control group (mean $\pm \mathrm{SEM}, n=4$ ) is represented by the shaded area in the line graphs comparing (b) animals fed $10(\bullet)$ and $17 \mu \mathrm{g} \mathrm{Zn} \mathrm{g}^{-1}(\mathrm{O})$ ad libitum and (c) deficient animals $\left(4 \mu \mathrm{g} \mathrm{Zn} \mathrm{g}^{-1}, \bullet\right)$ and pair-fed controls $\left(27 \mu \mathrm{g} \mathrm{Zn} \mathrm{g}^{-1}, 0\right)$. The shaded area in the histograms (d) represents the mean $( \pm \operatorname{SEM}, n=20$ ) of the area values observed before dietary treatments were imposed. ${ }^{a}$ b Values with different letters are significantly different (between-treatment comparison by least significant difference after analysis of variance; $P<0.05$ ).

The GnRH-induced LH pulses were larger than endogenous pulses (Martin and White, 1992); testicular responsiveness was therefore also assessed by measuring the concentrations of testosterone in samples from the $32 \mathrm{~h}$ pulse profiles. The selected samples followed an endogenous pulse that was, as far as possible, of average amplitude, isolated from other pulses and near the centre of the profile. This approach was judged valid on the following criteria; (i) the dietary treatments had no overall effect on LH pulse amplitude (Martin and White, 1992); (ii) the amplitudes of the LH pulses chosen for this test were similar for all groups except

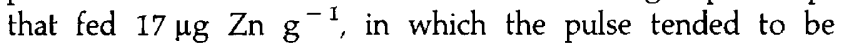
smaller, and (iii) the areas under the chosen LH and testosterone pulses were not significantly correlated $(r=0.12)$. Testosterone was assayed in samples from -40 to $240 \mathrm{~min}$, relative to the start of the $\mathrm{LH}$ pulse, and the values over 0-200 min were used to calculate the areas under the testosterone curves.

Inhibin concentrations were measured in plasma samples pooled every $2 \mathrm{~h}$ during all the pulse profiles.

\section{Hormone assays}

Plasma concentrations of $\mathrm{LH}$ and FSH were measured by radioimmunoassay as described in detail by Martin and White (1992).

Plasma concentrations of testosterone were measured in the weekly samples, those taken for the $3 \mathrm{~h}$ period following an endogenous LH pulse secreted near the middle of the intensive sampling period, and following the $\mathrm{LH}$ pulse released by the injection of GnRH. We used the radioimmunoassay described by Martin et al. (1987), with the following modifications: the ether extracts of two $100 \mu \mathrm{l}$ aliquots of plasma were dried and redissolved overnight at $4^{\circ} \mathrm{C}$ in $100 \mu \mathrm{l}$ of assay buffer containing the labelled hormone. The antiserum $(200 \mu \mathrm{l})$ was then added and the mixture incubated overnight at $4^{\circ} \mathrm{C}$ again, before being treated with $0.4 \mathrm{ml}$ of dextran-coated charcoal. After $15 \mathrm{~min}$, the tubes were centrifuged at $1600 \mathrm{~g}$ for $10 \mathrm{~min}$ and $0.5 \mathrm{ml}$ of the supernatant was mixed with $5 \mathrm{ml}$ of scintillant and counted. The anti-testosterone serum (no. 457) had been raised against testosterone-3-carboxy-methyl-oxime Downloaded from Bioscientifica.com at 04/26/2023 01:08:54AM 

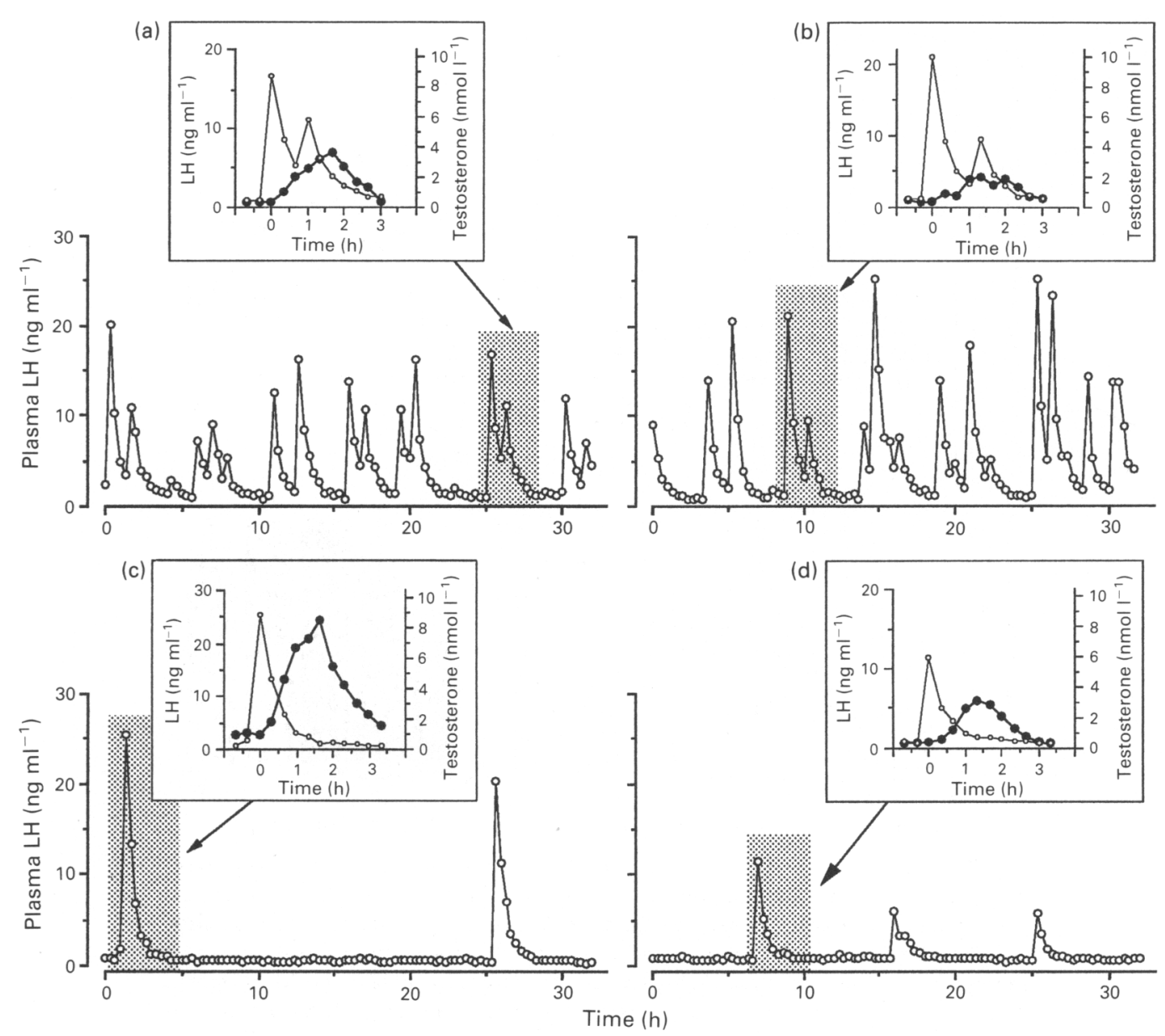

Fig. 3. Examples of LH (O) and testosterone (•) profiles observed before (a, b) and after (c, d) 92 days of dietary treatment from a pair-fed control ram $(a, c)$ and a zinc-deficient ram $(b, d)$.

BSA in sheep, and displayed only a few significant crossreactions: $5 \alpha$-dihydrotestosterone, $98 \%$; 4 -androsten- $3 \beta, 17 \beta$-diol, $47 \%$; 4-androsten-3,17-dione, 4.7\%; 4-androsten-17,19-diol-3one, $3.6 \%$; and androsterone, $1.0 \%$ (R. I. Cox, personal communication). The limit of detection was $0.42 \pm 0.07 \mathrm{nmol}^{-1}$. The non-specific binding was $2.2 \pm 0.13 \%$. Included in each assay were six replicates of three pooled plasma samples containing 5.24, 6.93 and $13.3 \mathrm{nmol} 1^{-1}$. They were used to estimate the coefficients of variation within assays $(14.0 \pm 1.9 \%, 6.5 \pm 0.6 \%$ and $12.1 \pm 1.7 \%$, respectively) and between assays ( $18.5 \%, 9.0 \%$ and $10.2 \%$, respectively).

Testicular testosterone was determined in single samples of frozen tissue (about $1 \mathrm{~g}$ ) from each ram that were weighed and chopped into small pieces before being homogenized in $5 \mathrm{ml}$ buffer (10 mmol phosphate $\mathrm{I}^{-1}, 1 \mathrm{mmol}$ EDTA $\mathrm{l}^{-1}, 140 \mathrm{mmol}$ $\left.\mathrm{NaCl} \mathrm{l}^{-1}, 15.4 \mathrm{mmol} \mathrm{NaN}_{3} 1^{-1}, \mathrm{pH} 7.5\right)$. The homogenates were centrifuged $(1500 \mathrm{~g}, 20 \mathrm{~min})$; the resultant pellets were resuspended in $5 \mathrm{ml}$ buffer; and both the pellets and supernatants of each sample were extracted with ether and assayed as above. The masses from each portion were combined for an estimate of tissue content.

Inhibin was measured using the double antibody radioimmunoassay described in detail by McNeilly et al. (1989). In brief, the antiserum (R150) was raised in a rabbit immunized against a synthetic 1-26 sequence of the $\alpha$ chain of porcine inhibin. At a final dilution of 1:75000, it specifically bound $24 \%$ of labelled antigen. The synthetic peptide was used as reference, and as a tracer after it was labelled with ${ }^{125}$ I by the chloramine-T method. An amount of plasma equivalent to that in the samples was added to each standard. The limit of detection was $0.08 \mu \mathrm{g} \mathrm{l}^{-1}$ plasma and non-specific binding was $2.4 \%$. All samples were measured in a single assay, which included six replicates of three pooled plasma samples containing $2.79,1.17$ and $1.55 \mu \mathrm{g} \mathrm{l}^{-1}$. They were used to estimate the coefficients of variation within assays $(4.8,6.1$ and $4.4 \%$, respectively).

\section{Testicular histology}

Samples were taken from one testis of each ram and fixed in $10 \%$ neutral formalin. The samples were post-fixed in osmium tetroxide in $0.1 \mathrm{~mol}$ phosphate buffer $1^{-1}$, dehydrated by a series of alcohols $(50 \%, 70 \%, 90 \%, 100 \%)$ and $100 \%$ acetone, and then embedded in glycolmethacrylate.

Blocked specimens from each testis were trimmed and a $2 \mu \mathrm{m}$ section was cut using a JB4 microtome with a glass knife. Sections were stained with haematoxylin and eosin. For Downloaded from Bioscientifica.com at 04/26/2023 01:08:54AM 
(a)

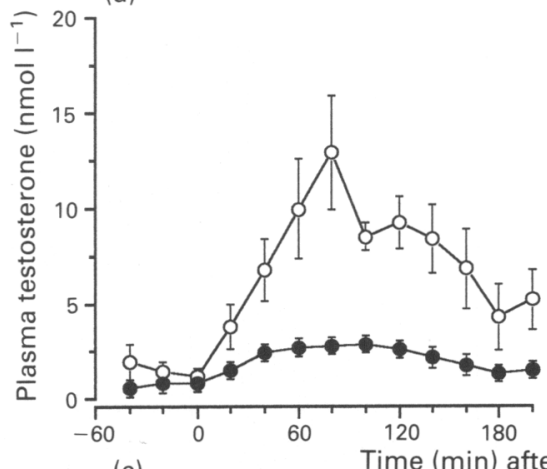

(c)

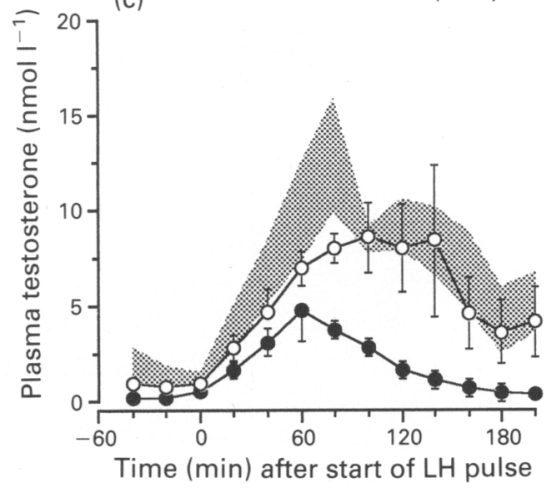

(b)

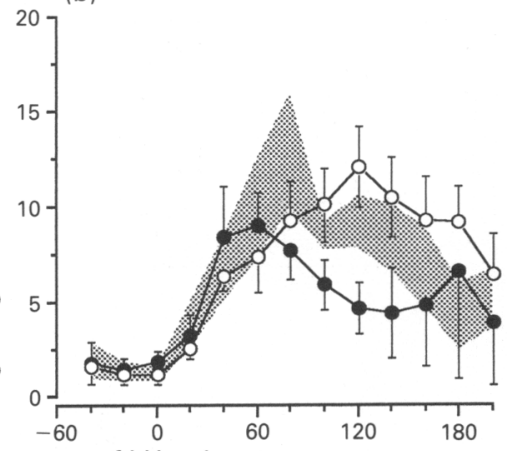

(d)

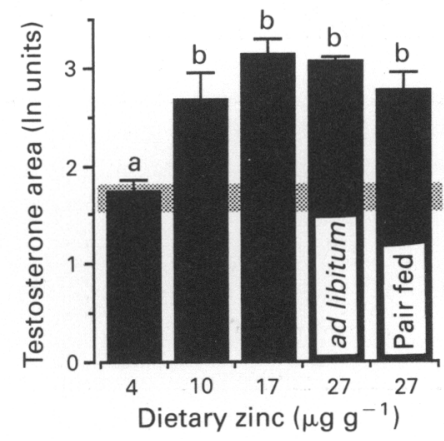

Fig. 4. Effects of dietary zinc on the testicular response of young male sheep to an endogenous LH pulse. (a) The pretreatment response ( $\bullet$ for the whole group $(n=20)$ is compared with the response of the group fed $27 \mu \mathrm{g} \mathrm{Zn} \mathrm{g}^{-1}$ ad libitum for 96 days (0). For comparison, the data from this control group (mean \pm SEM, $n=4$ ) is represented by the shaded area in the line graphs comparing (b) animals fed $10(\bullet)$ and $17 \mu \mathrm{g} \mathrm{Zn}^{-1}$ (O) ad libitum and (c) deficient animals (4 $\mu \mathrm{g} \mathrm{Zn}^{-1}, \bullet$ ) and pair-fed controls $\left(27 \mu \mathrm{g} \mathrm{Zn} \mathrm{g}^{-1}, 0\right)$. The shaded area in the histograms (d) represents the mean ( $\pm \mathrm{SEM}, n=20$ ) of the area values observed before dietary treatments were imposed. ${ }^{a}$, $V$ alues with different letters are significantly different (between-treatment comparison by least significant difference after analysis of variance; $P<0.05$ ).

stereological analysis of testicular morphology (relative composition of spermatogenic epithelium, seminiferous tubule lumen and interstitial tissue), each section was viewed at $\times 25$ magnification through a Wild Leitz microscope fitted with an eyepiece containing a multipurpose test system M42 (Weibel, 1979). The quantitative methodology for this study was based on the stereological principles and techniques described by Weibel and Gomez (1962).

The diameters of the seminiferous tubules and their lumens were measured by fitting a graticule of a calibrated linear scale in the $\times 10$ eyepiece of a Wild Leitz microscope at objective lens $\times 40$. In each section, only those tubules that were circular, or near circular, in profile were measured, ensuring that an accurate cross-section of the tubule was assessed. The height of the seminiferous epithelium was calculated by subtracting the lumen diameter from the tubule diameter.

All tissue variables were assessed by viewing four randomly chosen areas per section of tissue. Each testis was represented by one section from three tissue blocks. There were four rams per experimental group, so a total of 48 areas were measured for each treatment. The mean data from each animal were analysed statistically.

\section{Statistical analysis}

One-way analysis of variance was used for most comparisons. Data containing a time component were tested for time and treatment effects by repeated measures analysis of variance and, when significant effects were detected, individual means were compared using the least significant difference $(P=0.05)$. Where the variance was proportional to the mean, the data were transformed logarithmically before statistical analysis.

\section{Results}

\section{Live mass, feed intake and plasma zinc}

These data have already been presented in detail (Martin and White, 1992), and are summarized as follows. Feed intake was severely reduced in the zinc-deficient animals $\left(4 \mu \mathrm{g} \mathrm{Zn} \mathrm{g}^{-1}\right.$ ) relative to all groups except the pair-fed control group. There were no significant differences between the groups fed 10, 17 or $27 \mu \mathrm{gn} \mathrm{g}^{-1}$ ad libitum. The live masses of the animals at the end of the experiment reflected the feed
Downloaded from Bioscientifica.com at $04 / 26 / 2023$ 01:08:54AM 


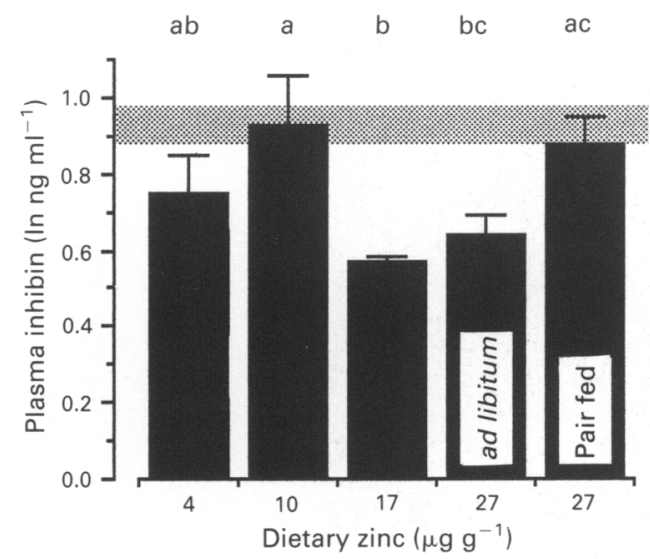

Fig. 5. Effects of dietary zinc on the plasma concentrations of inhibin in young male sheep, before and after 96 days of treatment. The shaded area represents the mean ( $\pm \mathrm{SEM}, n=20$ ) of the inhibin concentrations observed before dietary treatments were imposed. $a, b, c$ Values with different letters are significantly different (betweentreatment comparison by least significant difference after analysis of variance; $P<0.05$ ).

intakes, with very little growth shown in the animals fed $4 \mu \mathrm{gn} \mathrm{g}^{-1}$ or $27 \mu \mathrm{gn} \mathrm{g}^{-1}$ pair-fed, and the same amount of growth in all other groups. The concentration of zinc in blood plasma was correlated with dietary content, the group fed $4 \mu \mathrm{g} \mathrm{Zn} \mathrm{g}^{-1}$ showing values in the deficient range $\left(<0.2 \mathrm{mg} \mathrm{I}^{-1}\right)$, which were significantly below those for both pair-fed and ad libitum controls ( $>0.6 \mathrm{mg} \mathrm{l}^{-1}$ ). The values for the group fed $10 \mathrm{\mu g} \mathrm{g}^{-1}$ were intermediate between those observed in the deficient and ad libitum control groups (>0.4 $\mathrm{mg} \mathrm{l}^{-1}$ ).

\section{Testicular size and development}

The effects of diet on paired testicular mass and paired epididymal mass were significant $(P=0.0001$; analysis of variance). Between-group comparisons showed that, for both epididymis and testis, the organ masses did not differ significantly between the animals fed 10, 17 or $27 \mu \mathrm{gn} \mathrm{g}^{-1}$ ad libitum, but were significantly lower in pair-fed controls, and lowest in the deficient animals (Fig. 1a, b). When the data for the rams fed 17 and $27 \mu \mathrm{g} \mathrm{Zn} \mathrm{g}{ }^{-1}$ ad libitum were combined, they had significantly larger testes than did the rams fed $10 \mu \mathrm{g} \mathrm{Zn} \mathrm{g}^{-1}$ (177.7 versus $137.0 \mathrm{~g} ; P=0.03$ ), in accordance with the effects on growth estimated by measurement of testicular diameter with calipers (Martin and White, 1992). Testicular concentrations of zinc were lower in the deficient animals than in all the other groups (Fig. 1c). Testicular concentrations of testosterone were highly variable, but the values were significantly lower in deficient animals than in non-deficient animals when the data for all the other groups were pooled (Fig. 1d).

\section{Gonadotrophin secretion}

These data have already been presented in detail (Martin and White, 1992), and are summarized as follows. There was a general decrease in LH pulse frequency as the experiment (and pubertal development) progressed, but the size of the effect varied markedly between dietary treatments. In the animals fed 10 or $17 \mu \mathrm{Zn} \mathrm{g}^{-1}$, the frequency of pulses remained similar to pretreatment values, whereas it fell significantly in the ad libitum controls. The largest falls were observed in the deficient and pair-fed animals, for which the values were not significantly different from one another. The pulse frequencies in these two groups were also lower than those observed in the ad libitum controls $\left(27 \mu \mathrm{g} \mathrm{g}^{-1}\right)$, but the difference was not significant. The mean concentration of $\mathrm{LH}$ was affected by diet in the same way as pulse frequency, but pulse amplitude did not differ between treatments.

In contrast to $\mathrm{LH}$, the concentrations of FSH did not change significantly as the experiment progressed. In the final intensive sampling period, the concentration of FSH was significantly lower in the deficient animals than in the animals fed either 17 or $27 \mu \mathrm{g} \mathrm{Zn} \mathrm{g}^{-1}$ ad libitum. The values for the pair-fed controls were similar to those of the deficient animals and were also significantly lower than those in the ad libitum control group, but they did not differ from any other treatment.

The amplitudes of the $\mathrm{LH}$ pulses induced by exogenous $\mathrm{GnRH}$ ranged from 20 to $40 \mu \mathrm{g} \mathrm{l}^{-1}$, about twice the values observed for pulses secreted under endogenous control. Analysis of variance revealed no significant effect of time or diet on either the amplitude of the response or the area under the response curve.

\section{Testosterone secretion}

After GnRH injection. The data for the area under the testosterone curve $40-240 \mathrm{~min}$ after $\mathrm{GnRH}$ injection were logarithmically transformed and compared by analysis of variance (effect of diet: $P=0.015$ ). Comparison of the pretreatment values (all rams grouped) with the values for the ad libitum controls on day 92 shows that testicular responsiveness to $\mathrm{LH}$ increased substantially in most rams as the experiment progressed (Fig. 2a, d). The only exception was the deficient group, which produced less testosterone than did any of the other groups, including the pair-fed controls (Fig. 2c, d). There were no differences between any of the groups fed 10-27 $\mu \mathrm{g}$ $\mathrm{Zn} \mathrm{g}^{-1}$ in either the patterns of testosterone concentration or the amount of testosterone released (Fig. 2b, d).

Fig. 6. Photomicrographs of semi-thin sections of testis, stained with haematoxylin and eosin. (a) Testis from a ram fed ad libitum on a diet containing $27 \mu \mathrm{g} \mathrm{Zn} \mathrm{g}^{-1}$. Note the normal height of the spermatogenic epithelium and the open lumen (lu) in the cross-section of the seminiferous tubules (st), and the small area devoted to the interstitial region (ir) containing capillaries, connective tissue elements and Leydig cells. (b) Testis from a pair-fed control ram fed on a diet containing $27 \mu \mathrm{g} \mathrm{Zn} \mathrm{g}{ }^{-1}$. Compared with the ad lib controls, the seminiferous tubules are very small and very few of them have a lumen. Note the large areas of intertubular connective tissue in the interstitial region. (c) Testis from a ram fed on a zinc-deficient diet $\left(4 \mu \mathrm{g} \mathrm{Zn} \mathrm{g}{ }^{-1}\right)$. As in the pair-fed controls, the seminiferous tubules are very small and very few of them have a lumen. Note the large areas of intertubular connective tissue in the interstitial region. Scale bars represent $100 \mu \mathrm{m}$. 

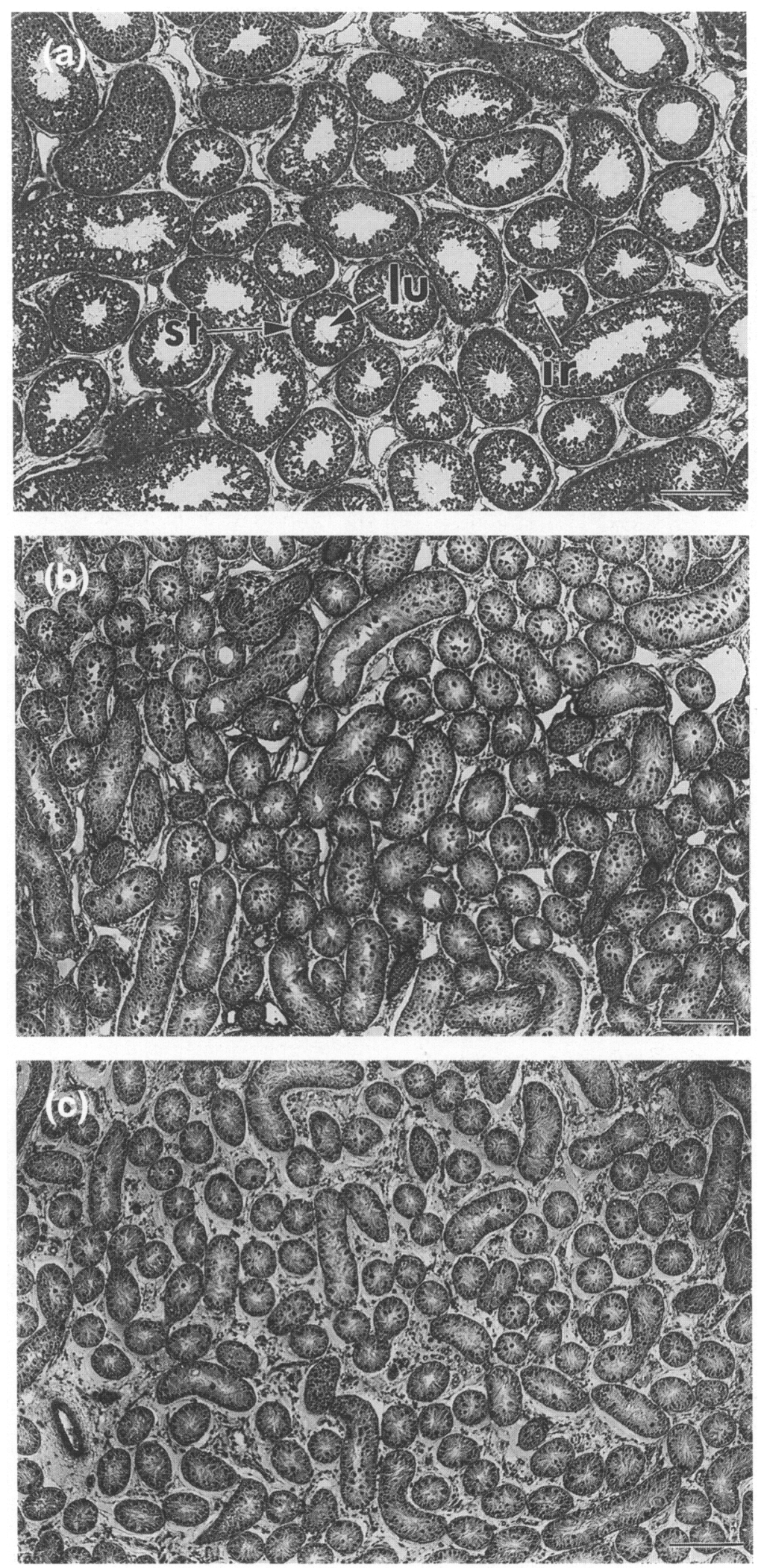


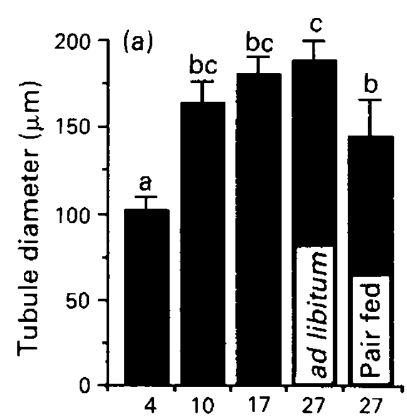

(d)

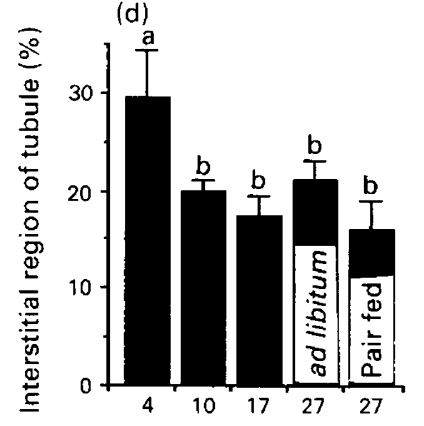

(b)

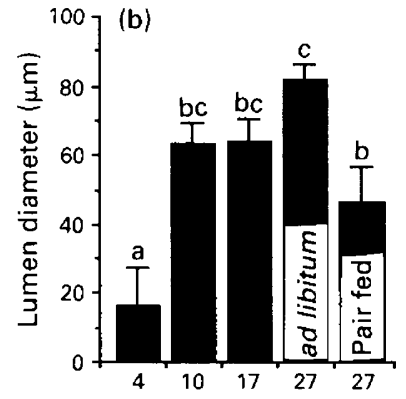

(e)

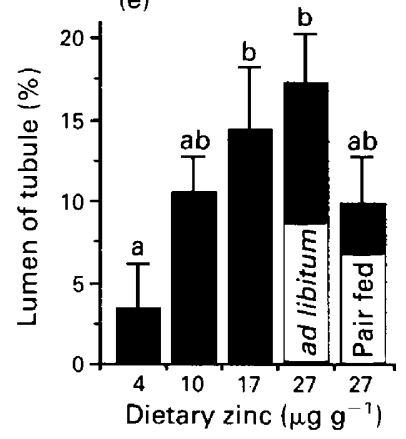

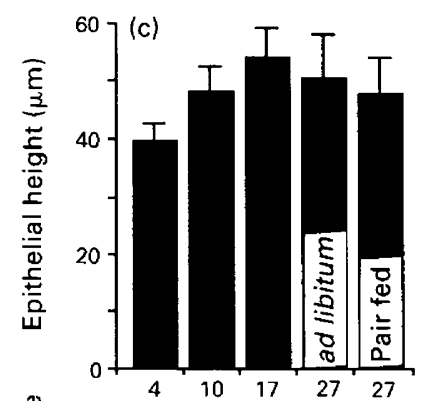

(f)

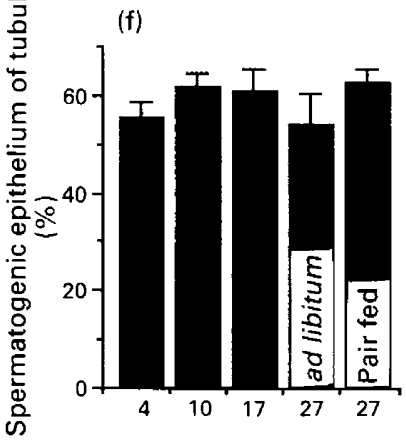

Fig. 7. Morphometric analysis of the effects of dietary zinc on testicular tissue in young male sheep after 96 days of treatment. All values are means $\pm \operatorname{SEM}(n=4) .{ }^{a}$, b c Values with different letters are significantly different (between-treatment comparison by least significant difference after analysis of variance; $P<0.05$ ).

Induction by endogenous $L H$ pulses. Pulses of testosterone followed each pulse of LH (Fig. 3) and the areas under the testosterone curves were transformed logarithmically and the resulting data were compared by one-way analysis of variance (effect of diet: $P=0.0003$ ). Overall, the values and responses to time and dietary treatment were similar to those observed after the GnRH test (Fig. 4). In the groups fed 10-27 $\mu \mathrm{g} \mathrm{Zn} \mathrm{g}^{-1}$ ad libitum, there was a substantial increase in the amount of testosterone produced by each $\mathrm{LH}$ pulse as the experiment progressed. Of particular interest is the fact that, at the end of the experiment (day 92), the pair-fed controls, in which there was little testicular growth, produced an amount of testosterone per pulse that was similar to the ad libitum controls. This result contrasted with the deficient group, in which there was no significant change as the experiment progressed (Figs 3, 4).

\section{Plasma inhibin concentrations}

Analysis of covariance revealed no relationship between the pretreatment values and values taken on day 96. Repeated measures analysis of variance showed significant interaction between time and treatment $(P=0.048)$ reflecting the falls in inhibin concentration as the experiment progressed in groups fed 17 and $27 \mu \mathrm{g} \mathrm{Zn} \mathrm{g}^{-1}$ ad libitum (Fig. 5). One-way analysis of variance on values taken on day 96 showed significant differences between these groups and the animals fed $10 \mu \mathrm{gn} \mathrm{g}^{-1}$, and between the pair-fed control and the group fed $17 \mu \mathrm{g} \mathrm{Zn} \mathrm{g}{ }^{-1}$. The difference between the two groups fed $27 \mu \mathrm{g} \mathrm{Zn} \mathrm{g}{ }^{-1}$ approached significance $(P=0.06)$. Inhibin and FSH concentrations were not related $\left(r^{2}=0.075\right)$.

\section{Testicular morphometry and histology}

In the testicular tissue, the pair-fed control rams showed less tubule growth and lumen development than did the ad libitum controls (Fig. 6); the controls were similar to the animals fed 10 or $17 \mu \mathrm{g} \mathrm{Zn} \mathrm{g}^{-1}$. In the deficient rams, the poor tubule development was even more evident and the interstitial regions appeared to be more extensive than in the other groups (Fig. 6). These observations were supported by the morphometric analysis: among the rams fed $10-27 \mu \mathrm{gn} \mathrm{g}^{-1}$ ad libitum, there were no significant differences in any of the variables measured (Fig. 7). Compared with the ad libitum controls, the pair-fed controls had tubules with a smaller overall diameter and a smaller lumen, but similar amounts of epithelial and interstitial tissue (Fig. 7). Compared with the pair-fed controls, the zinc-deficient animals had even smaller tubules, little or no lumen, and a larger proportion of interstitial tissue. There was no effect of treatment on the height of the epithelium of the seminiferous tubules.

\section{Discussion}

Zinc deficiency completely blocked testicular growth in young rams going through puberty. Comparison of the responses in the deficient animals with those in the pair-fed and ad libitum control groups showed that much of this effect was not a specific response to a lack of zinc, but was caused by the reduction of appetite. The resulting deficit in energy and protein needed for growth and pubertal development led to reductions in gonadotrophin secretion, very little of which was directly attributable to zinc deficiency (Martin and White, 
1992). However, the data presented also show that there were specific effects of zinc deficiency on several aspects of testicular development and function, particularly the secretion of testosterone.

Compared with the pair-fed controls, the zinc-deficient animals had more tissue devoted to interstitial cells, presumably including Leydig cells, but lower intratesticular testosterone concentrations and failed to develop fully an ability to secrete testosterone in response to LH. As has been reported for humans and rats, these observations indicate a role for zinc in the control of testosterone synthesis or secretion (Root et al., 1979; McClain et al., 1984; Prasad, 1985). This effect could be due to a malfunction in the LH receptor mechanism controlling storage and release of testosterone (Kellokumpu and Rajaniemi, 1981), a lesion in the biochemical systems controlling steroid synthesis (Prasad, 1985), or damage to the smooth endoplasmic reticulum of the Leydig cells, where testosterone is synthesized (Hesketh, 1982). The structural nature of steroid receptors also raises another possibility - zinc plays a key role as a component of the receptor that binds to DNA, confers specificity and regulates gene expression (the 'zinc finger' proteins; Green et al., 1988). Thus, reductions in testosterone secretion in zinc-deficient animals might be due to a loss in the effectiveness of steroid binding and the subsequent loss of a key protein or enzyme mediating the responses to $\mathrm{LH}$. Intratesticular testosterone is thought to be necessary for many aspects of normal testicular development and function, and the zinc-deficient animals had the smallest testes with the lowest concentration of testosterone; the effects we observed may therefore be due to a failure in cell-cell communications within the testis in which testosterone affects its own synthesis and secretion. On the other hand, zinc finger proteins are involved in several important biochemical processes, including reception of steroid vitamins and hormones (Parker, 1989); the observed effects might therefore also have been due to a loss in response to, for example, glucocorticoids. Clearly, this area requires investigation before firm conclusions can be drawn.

The results from comparable studies with zinc-deficient rats and humans differ from the present data in one key area, namely the balance between the concentrations of gonadotrophins and testosterone. In deficient rams, the concentrations of LH, FSH and testosterone are reduced (Martin and White, 1992), whereas in the other species, testosterone concentration is reduced and the concentrations of gonadotrophins are increased. Superficially, this observation of an increase in gonadotrophin secretion is more consistent with our understanding of the control of this secretion by the processes of negative feedback. The question is why does the ram differ? The data from the ad libitum and pair-fed controls provide part of the answer, showing that the restriction of feed intake strongly depressed hypothalamic activity. In zinc-deficient rams, it seems likely that this effect masked or blocked any responses to reduced negative feedback, a possibility that needs to be tested in castrated animals.

The data from this experiment reveal some interesting aspects of testicular development during puberty in rams. For example, the pair-fed control rams developed an ability to secrete normal amounts of testosterone in response to an $\mathrm{LH}$ pulse, yet the testes of these animals received very little gonadotrophic stimulation throughout that period, grew very little, and failed to develop normal seminiferous tubules. This observation leads to the surprising conclusion that the maturation of Leydig cells does not require high concentrations of $\mathrm{LH}$ and $\mathrm{FSH}$, although it is possible that these cells had fully developed before the appetite of the sheep was restricted by pair-feeding. Another interesting observation is the change in plasma inhibin concentrations during the experiment. Our inhibin assay would measure free $\alpha$ subunit, $\alpha-\alpha$ dimers as well as biologically active inhibin dimer, but the data nevertheless suggest that inhibin production, on a tissue mass basis, decreases as the seminiferous tubules mature. This is particularly evident when the animals with the smallest testes (pair-fed control and zinc-deficient) are compared with the animals with the largest testes. In the group fed $10 \mu \mathrm{g} \mathrm{Zn} \mathrm{g}^{-1}$, $\mathrm{LH}$ secretion tended to be lower (Martin and White, 1992), testicular growth was slow and inhibin production did not decrease. Taken together, these data lend some support to the contention by Underwood and Somers (1969) that young rams require a higher concentration of zinc in the diet for testicular growth than for the growth of other body tissues. However, we observed maximum body growth at $27 \mu \mathrm{g} \mathrm{Zn} \mathrm{g}^{-1}$ (Martin and White, 1992) and maximum testicular growth at $17 \mu \mathrm{g} \mathrm{Zn} \mathrm{g}^{-1}$, an observation that is consistent with the value of $22 \mu \mathrm{g} \mathrm{g}^{-1}$ proposed by Hatch et al. (1987) but not the value of $32 \mu \mathrm{g} \mathrm{g}^{-1}$ proposed by Underwood and Somers (1969).

In conclusion, the reduction of testicular growth and retardation of tubule development caused by zinc deficiency is due to the combined effects of a specific response (caused by the loss of zinc) and a non-specific response (inhibition of gonadotrophin secretion caused by the loss of appetite). Since gonadotrophin secretion is not directly affected by zinc deficiency, the zinc-specific effect appears to be localized within the testis where it prevents full development of the capacity to produce testosterone, probably through a biochemical disruption of Leydig cell function. This leads to low intratesticular concentrations of testosterone. Thus, the poor development of seminiferous tubules in the zinc-deficient animals was probably caused by the combined effects of low plasma concentrations of FSH (Martin and White, 1992) and low intratesticular concentrations of testosterone, as both of these factors are critical for tubular growth, development and function (Kerr et al., 1992). In the pair-fed controls, however, FSH concentrations were low, but tubule development was less severely retarded because intratesticular testosterone concentrations were normal. A fall in plasma concentrations of inhibin seems to be associated with puberty; the maintenance of inhibin concentration in the zinc-deficient rams may therefore be a side-effect associated with the failure of tubule development and it may indicate a role for zinc in this process.

This work was supported by a Joint CSIRO-University of Western Australia Research Grant and grants from the Australian Wool Corporation and the Australian Research Council. The authors would like to thank S. W. Walkden-Brown and N. R. Adams for reviewing the manuscript, and the following people for their technical assistance: M. Barnes, J. Briegel, M. Sanders, P. Cransberg, R. Holmes, S. Roe and D. Suckling. We are especially grateful to Dr J. B. Kerr of Monash University for his advice on the histology.

Downloaded from Bioscientifica.com at 04/26/2023 01:08:54AM 


\section{References}

Green S, Kumar V, Theulaz I, Whali $W$ and Chambon $P$ (1988) The N-terminal DNA-binding 'zinc finger' of the oestrogen and glucocorticoid receptors determines target gene specificity EMBO Journal 7 3037-3044

Hatch PA, Spears JW, Goode L and Johnson BH (1987) Influence of dietary zinc on growth and testicular development in ram lambs fed a high fiber diet Nutrition Reports International 35 1175-1183

Hesketh JE (1982) Effects of dietary zinc deficiency on Leydig cell ultrastructure in the boar Journal of Comparative Pathology 92 239-247

Kellokumpu S and Rajaniemi H (1981) Effect of zinc on the uptake of human chorionic gonadotropin ( $\mathrm{hCG}$ ) in rat testis and testosterone response in vivo Biology of Reproduction 24 298-305

Kerr JB, Maddocks S and Sharpe RM (1992) Testosterone and FSH have independent, synergistic and stage-dependent effects upon spermatogenesis in the rat testis Cell and Tissue Research 268 179-189

Lei KY, Abbasi AA and Prasad AS (1976) Function of the pituitary-gonadal axis in zinc-deficient rats American Joumal of Physiology 230 1730-1732

McClain CJ, Gavaler IS and van Thiel DH (1984) Hypogonadism in the zinc-deficient rat: localization of the functional abnormalities Joumal of Laboratory and Clinical Medicine 104 1007-1015

McNeilly AS, Swanston IA, Crow W, Tsonis CG and Baird DT (1989) Changes in the plasma concentrations of inhibin throughout the normal sheep oestrous cycle and after the infusion of FSH Journal of Endocrinology 120 295-305

Martin GB and White CL (1989) Effects of dietary zinc deficiency on testicular growth and gonadotrophin secretion in rams Proceedings of the Australian Society for Reproductive Biology 2111
Martin GB and White CL (1992) Effects of dietary zinc deficiency on gonadotrophin secretion and testicular growth in young male sheep Journal of Reproduction and Fertility 96 497-507

Martin GB, Sutherland SRD and Lindsay DR (1987) Effects of nutritional supplements on testicular size and the secretion of $\mathrm{LH}$ and testosterone in Merino and Booroola rams Animal Reproduction Science 12 267-281

Masters DG and Fels HF (1980) Effect of zinc supplementation on the reproductive performance of grazing Merino ewes Biological Trace Element Research 2 281-290

Masters DG and Somers M (1980) Zinc status of grazing sheep: seasonal changes in zinc concentrations in plasma, wool and pasture Australian joumal of Experimental Agriculture and Animal Husbandry 20 20-24

Parker MG (1989) Control of gene transcription by steroid hormones joumal of Endocrinology 123 (Supplement) Abstract 2

Prasad AS (1985) Clinical, endocrinological and biochemical effects of zinc deficiency Clinics in Endocrinology and Metabolism 14 567-589

Root AW, Duckett G, Sweetland M and Reiter EO (1979) Effects of zinc deficiency upon pituitary function in sexually mature and immature male rats Joumal of Nutrition 109 958-964

Underwood EJ and Somers M (1969) Studies on zinc nutrition in sheep. I. The relation of zinc to growth, testicular development and spermatogenesis in young rams Australian Journal of Agricultural Research 20 889-897

Weibel ER (1979) In Practical Methods for Biological Morphometry (Stereological Methods, Vol. 1). Academic Press, London

Weibel ER and Gomez DM (1962) A principle for counting tissue structures on random sections Journal of Applied Physiology 17 343-348 